\title{
Harris Hawks Optimization for Optimum Design of Truss Structures with Discrete Variables
}

\author{
Mustafa Al-Bazoon \\ Department of Civil Engineering, College of Engineering, \\ The University of Misan, Amarah, Maysan, Iraq. \\ E-mail: mustafa-jasim@uomisan.edu.iq
}

(Received on January 21, 2021; Accepted on June 15, 2021)

\begin{abstract}
This article investigates the use of Harris Hawks Optimization (HHO) to solve planar and spatial trusses with design variables that are discrete. The original $\mathrm{HHO}$ has been used to solve continuous design variables problems. However, HHO is formulated to solve optimization problems with discrete variables in this research. HHO is a population-based metaheuristic algorithm that simulates the chasing style and the collaborative behavior of predatory birds Harris hawks. The mathematical model of HHO uses a straightforward formulation and does not require tuning of algorithmic parameters and it is a robust algorithm in exploitation. The performance of HHO is evaluated using five benchmark structural problems and the final designs are compared with ten state-of-the-art algorithms. The statistical outcomes (average and standard deviation of final designs) show that HHO is quite consistent and robust in solving truss structure optimization problems. This is an important characteristic that leads to better confidence in the final solution from a single run of the algorithm for an optimization problem.
\end{abstract}

Keywords- Harris hawks optimization algorithm, Discrete structural optimization, Optimization of truss structures.

\section{Introduction}

For several decades, the development of optimization methods for structures has attracted considerable attention to achieving economic designs. In many real-life design cases, structures are geometrically complex and consist of a large number of members. In size optimization, these members are variables to be designed for minimal weight under certain limitations imposed by a design code. Thus, the optimization process requires considerable computational effort because the number of structural members to be designed is high. Thus, an efficient and robust optimization algorithm is vital for the optimization of structures.

Deterministic optimization methods (e.g., linear programming (LP), nonlinear programming (NLP), and dynamic programming (DP)) were developed more than 50 years ago. They need gradient information to improve the current solution estimate and they search for designs in the proximity of the current point (Arora, 2017). These methods were mainly developed to solve problems with design variables that are continuous. Most design applications in structural engineering; however, involve selecting sections available in commercial catalogs. In this type of problem, the design variables are discrete. Namely, they are integers where the value that is signed to a design variable refers to a specific selection in the design set. Metaheuristic algorithms (such as Genetic Algorithm (Goldberg and Samtani, 1986), Ant Colony Optimization (Xie and Steven, 1997), and Particle Swarm Optimization (Kennedy and Eberhart, 1995) are another optimization approach. They utilize only simulation results to search for solutions. These algorithms do not require starting points and they search not only in the proximity of the current design but also globally. Metaheuristic algorithms can be used to solve continuous and discrete design variables 
problems whether functions (cost function and constraints) are differentiable or not. The fundamental disadvantage of metaheuristic algorithms is that they relatively require a large number of simulations to improve designs. The computation time relies on the size of the structure, type of analysis (e.g., static, dynamic, linear, or nonlinear), the number of members to be designed, and the number of sections in the design domain. These algorithms may get trapped in local minima. The best approach is to run the algorithm more than once and choose the best solution among different runs. However, this requires more computational time (Al-Bazoon, 2019). In recent years, many studies have been dedicated to developing robust and efficient metaheuristic techniques for the optimization of structures.

Many metaheuristic algorithms were used to tackle discrete variables truss structure problems. Rajeev and Krishnamoorthy (1992) and Wu and Chow (1995) used the Genetic Algorithm (GA) to solve discrete variables optimization structural problems. Harmony Search (HS) was used by Lee et al. (2005) to solve structural optimization problems where members must be selected from set of sections. Li et al. (2006) solved some benchmark structural optimization problems using Particle Swarm Optimization (PSO). Other algorithms such as Simulated Annealing (SA) by Xiang et al. (2009), Big Bang-Big Crunch (BB-BC) by Camp (2007), Improved Ray Optimization (IRO) by Kaveh and Mahdavi (2015), Hybrid Harmony Search-Particle Swarm Optimizer-Ant Colony (DHPSACO) by Kaveh and Talatahari (2009), Colliding Bodies Optimization (CBO) and its improved version called Enhanced Colliding Bodies Optimization (ECBO) by Kaveh and Mahdavi (2015) were used to find the minimal structural weight of truss problems. A hybrid algorithm combined biogeography-based optimization and differential evolution method was used to find the minimal structural weight of trusses with discrete and continuous variables (Jalili and Hosseinzadeh, 2018). In 2020, another hybrid algorithm is developed and used to design truss structures (Omidinasab and Goodarzimehr, 2020). The algorithm is based on Particle Swarm Optimization and Genetic Algorithm. Although many of these algorithms found the optimal design for the problems discussed in this study, they require many iterations to find the best design, and the mean and standard deviation of all runs show that they are not very robust. In addition, they required algorithmic parameter(s) to be tuned of which is problem-dependent.

Harris Haws Optimization has been utilized to tackle optimization problems in many fields such as overcurrent relay coordination problems (Yu et al., 2020), image processing (Rodríguez-Esparza et al., 2020; Wunnava et al., 2020), chemical engineering (Houssein et al., 2020), and mechanical engineering (Ewees and Abd Elaziz, 2020). HHO outperforms many well-known metaheuristic algorithms as to convergence rate and statistical analysis. That is, the major motivation for this work is to investigate the use of HHO to solve truss structure optimization problems with design variables selected from a set of sections. The original HHO was designed to tackle optimization problems with continuous design variables problems. In this study, however, HHO is modified so that it can suit the discrete design variables problems. HHO has not been used to solve truss optimization problems with design variables that are discrete, to the author's knowledge.

The remainder sections are arranged as follows: Section 2 presents the formulation of the problem. HHO is reviewed briefly and the main changes to make it suitable for discrete design variables problems are described in Section 3. The reader is referred to Heidari et al. (2019) for details about HHO. The design examples and the outcomes are discussed in Section 4. Lastly, the conclusions of this study are discussed in Section 5. 


\section{Formulation of the Optimization Problems}

When structural components have to be chosen from available sections in a manufacture's catalog, they must be considered discrete design variables. The formulation of discrete design variables optimization problem can be written as:

Find $\boldsymbol{x}=\left[x_{1}, x_{2}, \ldots, x_{n}\right] ; \quad x_{i} \in D_{i} ; \mathrm{i}=1,2, \ldots, n$

$\min f(\boldsymbol{x})$

s.t. $g_{l}(\boldsymbol{x}) \leq 0 ; \quad l=1,2, \ldots, p$

where $\boldsymbol{x}$ is the vector of design variables with $n$ members, $D_{i}$ is a set of members (in this study, it is set of cross-section areas) for the $i$ th design variable, $f(\boldsymbol{x})$ is a cost function (in this research, $f(\boldsymbol{x})$ is the total weight or mass of the truss), and $g_{l}(\boldsymbol{x})$ is $l$ th a constraint function.

Constraints are combined with the cost function to generate a penalty function. Then, it is minimized:

$F(\boldsymbol{x})=f(\boldsymbol{x})[1+\psi G(\boldsymbol{x})]^{\xi}$

$G(\boldsymbol{x})=\sum_{k=1}^{p} \max \left(0, g_{l}(\boldsymbol{x})\right)$

$\xi=3+2 * t / t_{\max }$

where, $G(\boldsymbol{x})$ is function sums all the violations if there is any, $\psi=10$ is an exploration penalty coefficient, $\xi$ is a penalty function exponent, $\max \left(0, g_{l}(\boldsymbol{x})\right) \geq 0$ is the violation value of the $l$ th constraint, $t$ is the present iteration, and $t_{\max }$ is the maximum number of iterations. Note that $F(\boldsymbol{x})$ exponent is increasing linearly from 3 to 5 (Kaveh and Mahdavi, 2015).

\section{Harris Hawks Optimization}

The algorithm simulates the behaviors of Harris hawks (birds of prey) of chasing a prey. Their chasing behavior is based on different possible escaping patterns of the prey (specifically rabbits). Harris hawks live in a very tied group. In nature, they show a distinguished cooperative foraging activities behavior with other family members. They use what is called "surprise pounce" or "seven kills" strategy. That is, seven hawks simultaneously attack a prey from various directions. Based on the escaping patterns of a prey, they change their chasing styles. When the prey is exhausted, the most experienced hawk among the group captures the exhausted prey and shares it with besiege (Heidari et al., 2019). In HHO, hawks are modeled as the possible solution (x).

In the HHO mathematical model, there are two states: exploration and exploitation. The best solution in every step is a potential optimum design in the exploration phase. The pseudocode of the HHO algorithm is explained in Algorithm. Hawks roost randomly on some positions to detect a rabbit using two strategies: the position of other members and the position of the rabbit. This behavior is modeled in Eq. (7).

$\boldsymbol{x}(t+1)=$ round $\begin{cases}\boldsymbol{x}_{\text {rand }}(t)-r_{1}\left|\boldsymbol{x}_{\text {rand }}(t)-2 r_{2} \boldsymbol{x}(t)\right| & q \geq 0.5 \\ \left(\boldsymbol{x}_{\text {rand }}(t)-\boldsymbol{x}_{m}(t)\right)-r_{3}\left(L_{b}+r_{4}\left(U_{b}-L_{b}\right)\right) & q<0.5\end{cases}$ 
$\boldsymbol{x}_{m}=\frac{1}{N} \sum_{i=1}^{N} \boldsymbol{x}_{i}(t)$

where, round is a function that rounds off every component in the design vector $\boldsymbol{x}$ to the closest integer. This is the main change on the original HHO to solve an optimization problem with discrete variables. $\boldsymbol{x}_{\text {rand }}(t)$ is the location of the rabbit, $r_{1}, r_{1}, r_{3}, r_{4}$, and $q$ are random values in the range of 0 and $1, L_{b}$ and $U_{b}$ are the variables' lower and upper bounds, respectively, $\boldsymbol{x}_{m}$ is the mean position of the current population of hawks, and $\boldsymbol{x}_{i}(t)$ is the position of each hawk in iteration $t$.

Depending on the escaping energy of the rabbit, HHO transfers from exploration to exploitation phases and between various exploitative styles. The mathematical model of the escaping energy of the rabbit is as follows:

$E=E_{0}\left(1-\frac{t}{t_{\max }}\right)$

$E_{0}=2 \operatorname{rand}()-1$

where, $E$ is the escaping energy and $E_{0}$ is the initial value of its energy. Note that the value of $E$ decreases as $t$ increases. When $1 \leq|E|$ the exploration phase happens, while the exploitation phase happens when $1>|E|$ in later iterations. In the exploitation phase, there are two besiege: soft and hard. That is when $0.5 \leq|E|$ the soft besiege happens and when $0.5>|E|$ the hard besiege happens. The soft besiege is mathematically modeled as follows:

$\boldsymbol{x}(t+1)=\operatorname{round}\left(\boldsymbol{x}_{\text {rabbit }}(t)-\boldsymbol{x}(t)-E\left|J \boldsymbol{x}_{\text {rabbit }}(t)-\boldsymbol{x}(t)\right|\right)$

$J=2\left(1-r_{5}\right)$

The mathematical form of the hard besiege is as follows:

$\boldsymbol{x}(t+1)=\operatorname{round}\left(\boldsymbol{x}_{\text {rabbit }}(t)-E\left|\boldsymbol{x}_{\text {rabbit }}(t)-\boldsymbol{x}(t)\right|\right)$

when $0.5>r$ and $0.5 \leq|E|$, the rabbit has enough energy to escape. The mathematical model of the escaping types of the prey and leapfrog movement $(\boldsymbol{L F})$ is modeled as follows:

$\boldsymbol{x}(t+1)=$ round $\begin{cases}\boldsymbol{y} & \text { if } F(\boldsymbol{y})<F(\boldsymbol{x}(t)) \\ \boldsymbol{z} & \text { if } F(\boldsymbol{z})<F(\boldsymbol{x}(t))\end{cases}$

$\boldsymbol{y}=\boldsymbol{x}_{\text {rabbit }}(t)-E\left|J \boldsymbol{x}_{\text {rabbit }}(t)-\boldsymbol{x}(t)\right|$

$z=y+s \times L F$

$\boldsymbol{L F}=\frac{\boldsymbol{u} \times 0.0069657}{|\boldsymbol{v}|^{1 / 1.5}}$

where, $F$ is the merit function, $\boldsymbol{s}, \boldsymbol{u}$, and $\boldsymbol{v}$ are random vectors by the size of $1 \times$ nvar. This step is called soft besiege with progressive rapid dives. In this paper, Eq. (17) is a simplified version of the original equation provided in Heidari et al. (2019). 
When $0.5>r$ and $0.5>|E|$, the rabbit does not have enough energy to escape. This step is called hard besiege with progressive rapid dives. The following rule is performed to mimic this behavior:

$$
\begin{aligned}
& \boldsymbol{x}(t+1)=\operatorname{round} \begin{cases}\boldsymbol{y} & \text { if } F(\boldsymbol{y})<F(\boldsymbol{x}(t)) \\
\boldsymbol{z} & \text { if } F(\boldsymbol{z})<F(\boldsymbol{x}(t))\end{cases} \\
& \boldsymbol{y}=\boldsymbol{x}_{\text {rabbit }}(t)-E\left|J \boldsymbol{x}_{\text {rabbit }}(t)-\boldsymbol{x}_{m}(t)\right| \\
& \boldsymbol{z}=\boldsymbol{y}+\boldsymbol{s} \times \boldsymbol{L}
\end{aligned}
$$

Algorithm. Pseudocode of Harris Hawks Optimization algorithm (Heidari et al., 2019).

Inputs: The population size $(N)$ and $t_{\max }$. Initialize the HHO population

Outputs: Best design $\left(\boldsymbol{x}_{\text {rabbit }}\right)$ and its fitness value

While $t<t_{\max }$

Find the fitness values of each design using Eq. (4)

Set $\boldsymbol{x}_{\text {rabbit }}$ as the current best design

For (every design $\left(\boldsymbol{x}_{i}\right)$ )

Update the initial energy $E_{0}$ (Eq. (10)), the energy $E$ (Eq. (9)), and the jump strength $J$ (Eq. (12))

$$
\text { If }(1 \leq|E|) \quad \text { (Exploration phase) }
$$

Calculate the position vector using Eq. (7)

$$
\text { If }(1>|E|)
$$

If $(0.5 \leq r$ and $0.5 \leq|E|)$

(Exploitation phase)

Calculate the position vector using Eq. (11)

Else if $(0.5 \leq r$ and $0.5>|E|)$

(Hard besiege)

Calculate the position vector using Eq. (13)

Elseif $(0.5>r$ and $0.5 \leq|E|) \quad$ (Soft besiege with progressive rapid dives)

Calculate the position vector using Eq. (14)

Elseif $(0.5>r$ and $0.5>|E|) \quad$ (Hard besiege with progressive rapid dives)

Calculate the position vector using Eq. (18)

Return $\boldsymbol{x}_{\text {rabbit }}$

\section{Numerical Examples}

Before the suggested HHO algorithm can be used to solve more complex and larger structural problems, it must be tested to solve some standard problems to study its performance. In the following subsections, five well-known truss optimization examples with design variables that should be selected from a defined set of members are solved to find the minimum weight or mass of the structure to compare the effectiveness of HHO with ten metaheuristic algorithms. Structures are modeled and analyzed using the finite element method (linear static analysis) and HHO is coded using $\mathrm{MATLAB}^{\odot}$. For all problems, $t_{\max }$ is set to 10000 iterations and $N$ is 50 .

Since HHO is stochastic, each example was run 50 times to examine the performance of HHO. Two metrics will be used in evaluations: (1) Average of the final merit function values obtained with different runs. An average value that is closer to the best solution will indicate the ability of the algorithm to obtain the best design more often. (2) Standard deviation (SD) of the final weight 
or mass. A smaller value of the standard deviation will imply robustness of the algorithm to obtain the best design with different runs for the problem.

\subsection{Planar Ten Bars Truss}

Figure 1 explains the schematic of the 10-bar truss. This benchmark structure has been discussed by several researchers, e.g., Rajeev and Krishnamoorthy (1992), Camp (2007), Li et al. (2009), Xiang et al. (2009), and others. For all members, Young's modulus is $10^{4} \mathrm{ksi}$, and the material density is $0.1 \mathrm{lb} / \mathrm{in}^{3}$. The maximum displacement for all joints in both $\mathrm{X}$ and $\mathrm{Y}$ directions equals $\pm 2.0 \mathrm{in}$. Also, the stress in all members must not surpass $\pm 25 \mathrm{ksi}$. The structure is subjected to two vertical downward loads, $\mathrm{P}=100$ kips, at joints 2 and 4 . Cross-sectional areas of all members are the design variables that are selected form the discrete set of 42 elements as follows: $D=[1.62,1.80$, $1.99,2.13,2.38,2.62,2.63,2.88,2.93,3.09,3.13,3.38,3.47,3.55,3.63,3.84,3.87,3.88,4.18$, $4.22,4.49,4.59,4.80,4.97,5.12,5.74,7.22,7.97,11.50,13.50,13.90,14.20,15.50,16.00,16.90$, $18.80,19.90,22.00,22.90,26.50,30.00,33.50]\left(\mathrm{in}^{2}\right)$.

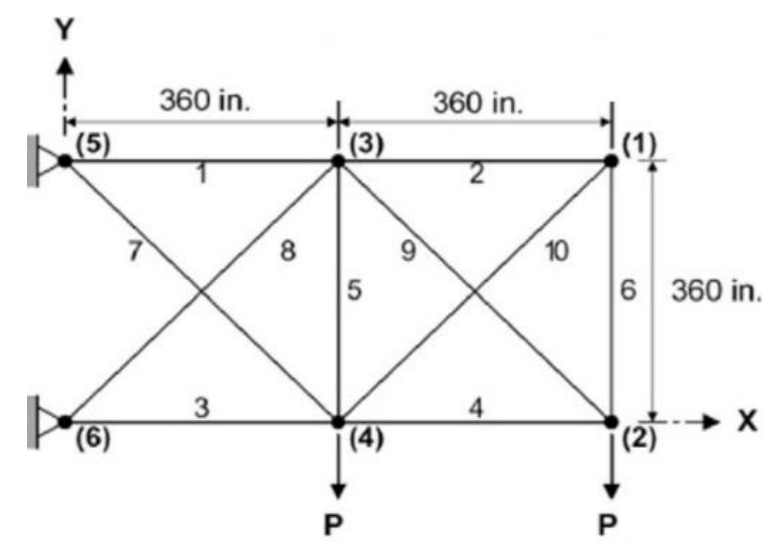

Figure 1. Schematic of 10-bar planar truss.

Table 1. Optimal designs for 10-bar truss.

\begin{tabular}{|c|c|c|c|c|c|c|}
\hline \multicolumn{2}{|c|}{ Design variable $\left(\mathbf{i n}^{2}\right)$} & \multirow{2}{*}{$\begin{array}{c}\text { GA } \\
\text { (Rajeev and } \\
\text { Krishnamoorthy, 1992) }\end{array}$} & \multirow{2}{*}{$\begin{array}{c}\text { HPSO (Li et } \\
\text { al., 2009) }\end{array}$} & \multirow{2}{*}{$\begin{array}{c}\text { SA (Xiang et } \\
\text { al., 2009) }\end{array}$} & \multirow{2}{*}{$\begin{array}{c}\begin{array}{c}\text { BB-BC (Camp, } \\
\text { 2007) }\end{array} \\
33.50 \\
\end{array}$} & \multirow{2}{*}{$\begin{array}{l}\text { HHO } \\
33.50\end{array}$} \\
\hline 1 & Area $_{1}$ & & & & & \\
\hline 2 & Area $_{2}$ & 1.62 & 1.62 & 1.62 & 1.62 & 1.62 \\
\hline 3 & $\mathrm{Area}_{3}$ & 22.00 & 22.90 & 22.90 & 22.90 & 22.90 \\
\hline 4 & Area $_{4}$ & 15.50 & 13.50 & 14.20 & 14.20 & 14.20 \\
\hline 5 & Area $_{5}$ & 1.62 & 1.62 & 1.62 & 1.62 & 1.62 \\
\hline 6 & Area $_{6}$ & 1.62 & 1.62 & 1.62 & 1.62 & 1.62 \\
\hline 7 & Area $_{7}$ & 14.20 & 7.97 & 7.97 & 7.97 & 7.97 \\
\hline 8 & Area $_{8}$ & 19.90 & 26.50 & 22.90 & 22.90 & 22.90 \\
\hline 9 & Area $_{9}$ & 19.90 & 22.00 & 22.00 & 22.00 & 22.00 \\
\hline 10 & Area $_{10}$ & 2.62 & 1.80 & 1.62 & 1.62 & 1.62 \\
\hline \multicolumn{2}{|c|}{ Best weight (lb) } & 5613.580 & 5531.984 & 5490.738 & 5490.738 & 5490.738 \\
\hline \multicolumn{2}{|c|}{$G($ Eq. 5) } & $3.77 \times 10^{-4}$ & None & None & None & None \\
\hline \multicolumn{2}{|c|}{ Average weight (lb) } & N/A & N/A & N/A & $5494.17^{\mathrm{a}}$ & 5490.738 \\
\hline \multicolumn{2}{|c|}{ SD weight $(\mathrm{lb})$} & N/A & N/A & N/A & 12.42 & 0 \\
\hline
\end{tabular}


Figure 2 demonstrates the best fitness at each iteration of the best run of HHO. The optimum design was obtained after 2430 iteration. Table 1 summarizes results available in the literature with four different algorithms and results from the present study. It also shows the mean values and standard deviations of the best structural weight from 50 independent for HHO. HHO was able to find the best design $(5490.738 \mathrm{lb})$. This is the same weight as obtained by SA, BB-BC, ECBO. However, $\mathrm{HHO}$ was able to find the optimal design in every run (the standard deviation of 50 runs is 0 ).

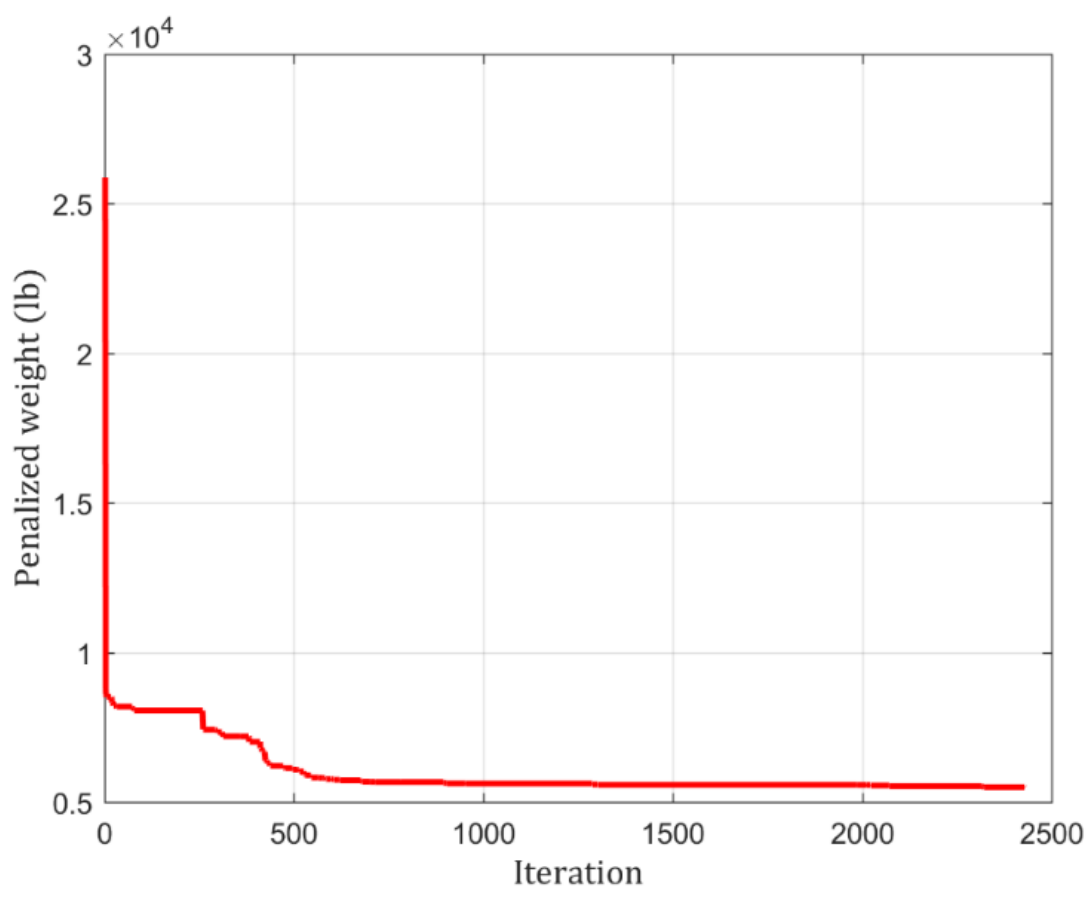

Figure 2. Convergence history for planar 10-bar truss (best run).

\subsection{Planar Fifteen Bars Truss}

Figure 3 explains the schematic of the 15-bar truss. Previously, this example was solved in Li et al. (2006) and Li et al. (2009). For all members, Young's modulus is $200 \mathrm{GPa}$ and material density is $7800 \mathrm{~kg} / \mathrm{m}^{3}$. The maximum displacement for all joints in both $X$ and $Y$ directions equals $\pm 10 \mathrm{~mm}$. Also, the stress in all members must not exceed $\pm 120 \mathrm{MPa}$. As shown in Figure 3, the structure is subjected to three vertical point loads with three independent load cases: case 1: $\mathrm{P}_{1}=35 \mathrm{kN}, \mathrm{P}_{2}=35$ $\mathrm{kN}$, and $\mathrm{P}_{3}=35$, case 2: $\mathrm{P}_{1}=35 \mathrm{kN}, \mathrm{P}_{2}=0 \mathrm{kN}$, and $\mathrm{P}_{3}=35$, and case $3: \mathrm{P}_{1}=35 \mathrm{kN}, \mathrm{P}_{2}=35 \mathrm{kN}$, and $\mathrm{P}_{3}=0$. Design variables are selected form the discrete set of 16 cross-sections: $D=[113.2,143.2$, 145.9, 174.9, 185.9, 235.9, 265.9, 297.1, 308.6, 334.3, 338.2, 497.8, 507.6, 736.7, 791.2, 1063.7] $\left(\mathrm{mm}^{2}\right)$. 


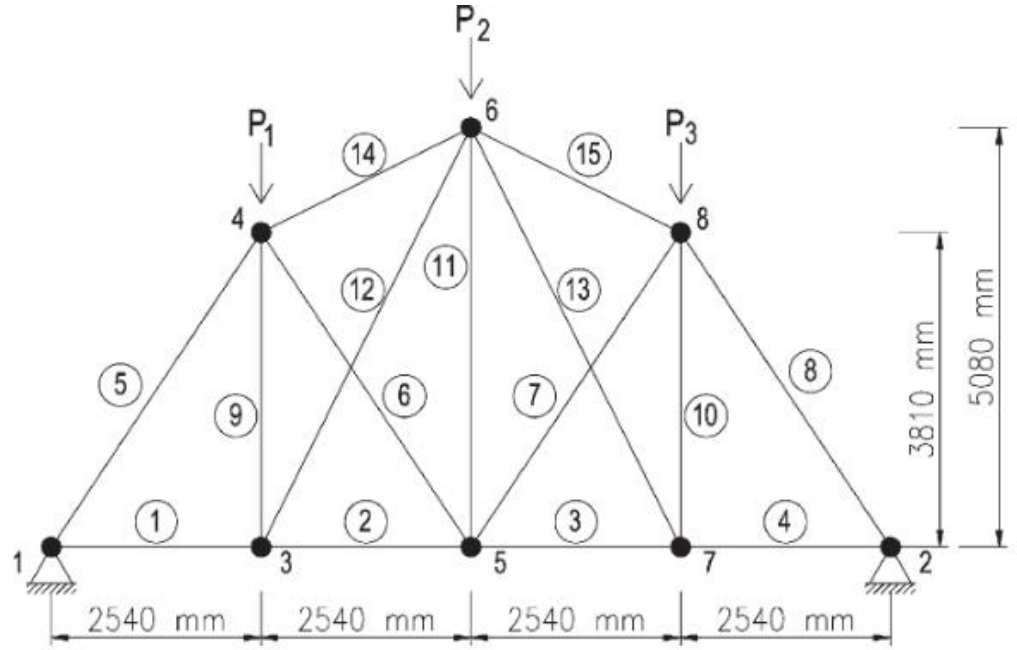

Figure 3. Schematic of 15-bar planar truss.

Figure 4 demonstrates the convergence curve of HHO. After 108 iterations $\mathrm{HHO}$ reaches the best design of $105.735 \mathrm{~kg}$. Similar to the previous numerical example, HHO finds the best design in each run. Table 2 shows that the average of 50 runs is $105.735 \mathrm{~kg}$ and the standard deviation is 0 .

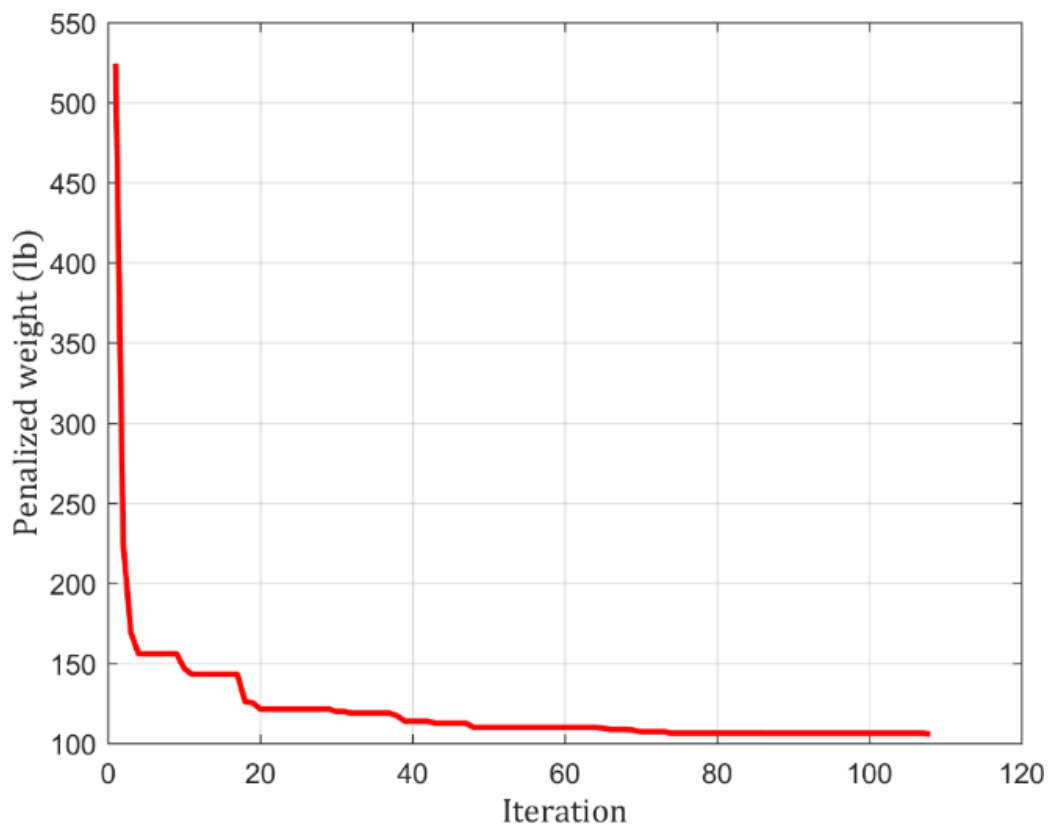

Figure 4. Convergence rate for planar 15-bar truss (best run). 
Table 2. Comparison of optimal designs for 15-bar truss problem.

\begin{tabular}{|c|c|c|c|c|}
\hline \multicolumn{2}{|c|}{ Design variables $\left(\mathrm{mm}^{2}\right)$} & PSO (Li et al., 2006) & HPSO (Li et al., 2009) & HHO \\
\hline 1 & Area $_{1}$ & 185.9 & 113.2 & 113.2 \\
\hline 2 & Area $_{2}$ & 113.2 & 113.2 & 113.2 \\
\hline 3 & Area $_{3}$ & 143.2 & 113.2 & 113.2 \\
\hline 4 & Area $_{4}$ & 113.2 & 113.2 & 113.2 \\
\hline 5 & Area $_{5}$ & 736.7 & 736.7 & 736.7 \\
\hline 6 & Area $_{6}$ & 143.2 & 113.2 & 113.2 \\
\hline 7 & Area $_{7}$ & 113.2 & 113.2 & 113.2 \\
\hline 8 & Area $_{8}$ & 736.7 & 736.7 & 736.7 \\
\hline 9 & Area $_{9}$ & 113.2 & 113.2 & 113.2 \\
\hline 10 & Area $_{10}$ & 113.2 & 113.2 & 113.2 \\
\hline 11 & Area $_{11}$ & 113.2 & 113.2 & 113.2 \\
\hline 12 & Area $_{12}$ & 113.2 & 113.2 & 113.2 \\
\hline 13 & Area $_{13}$ & 113.2 & 113.2 & 113.2 \\
\hline 14 & Area $_{14}$ & 334.3 & 334.3 & 334.3 \\
\hline 15 & Area $_{15}$ & 334.3 & 334.3 & 334.3 \\
\hline \multicolumn{2}{|c|}{ Best mass $(\mathrm{kg})$} & 108.841 & 105.735 & 105.735 \\
\hline \multicolumn{2}{|c|}{$G$ (Eq. 5) } & None & None & None \\
\hline \multicolumn{2}{|c|}{ Average mass (kg) } & N/A & N/A & 105.735 \\
\hline \multicolumn{2}{|c|}{ SD mass $(\mathrm{kg})$} & N/A & N/A & 0.0 \\
\hline
\end{tabular}

\subsection{Spatial Twenty-Five Bars Truss}

The schematic of this truss is shown in Figure 5. This example was solved in Rajeev and Krishnamoorthy (1992), Lee et al. (2005), Camp (2007), Li et al. (2009), Xiang et al. (2009), and Kaveh and Mahdavi (2015). For all members, Young's modulus is $10^{4} \mathrm{ksi}$, and the material density is $0.1 \mathrm{lb} / \mathrm{in} 3$. The maximum displacement for all joints in both $\mathrm{X}$ and $\mathrm{Y}$ directions is $\pm 0.35 \mathrm{in}$. In all members, the stress must not exceed $\pm 40 \mathrm{ksi}$. Two independent loading cases are applied as demonstrated in Table 3. This truss includes 25 members organized into 8 groups as given in Table 4. Members are selected form the discrete set of 30 elements: $D=[0.1,0.2,0.3,0.4,0.5,0.6,0.7$, $0.8,0.9,1.0,1.1,1.2,1.3,1.4,1.5,1.6,1.7,1.8,1.9,2.0,2.1,2.2,2.3,2.4,2.5,2.6,2.8,3.0,3.2$, 3.4] $\left(\mathrm{in}^{2}\right)$.

Table 3. Load cases of the 25-bar spatial truss.

\begin{tabular}{|c|c|c|c|c|c|}
\hline \multirow{2}{*}{ Case } & \multirow{2}{*}{ Load condition } & \multirow{2}{*}{ Nodes } & \multicolumn{3}{|c|}{ Loads (kips) } \\
\hline & & & $\mathbf{P}_{x}$ & $\mathbf{P}_{\mathbf{y}}$ & $\mathbf{P}_{\mathbf{z}}$ \\
\hline \multirow{4}{*}{1} & \multirow{4}{*}{1} & 1 & 1.0 & -10.0 & -10.0 \\
\hline & & 2 & 0.0 & -10.0 & -10.0 \\
\hline & & 3 & 0.5 & 0.0 & 0.0 \\
\hline & & 6 & 0.6 & 0.0 & 0.0 \\
\hline \multirow{6}{*}{2} & \multirow{2}{*}{1} & 1 & 0.0 & 20.0 & -5.0 \\
\hline & & 2 & 0.0 & -20.0 & -5.0 \\
\hline & \multirow{4}{*}{2} & 1 & 1.0 & 10.0 & -5.0 \\
\hline & & 2 & 0.0 & 10.0 & -5.0 \\
\hline & & 3 & 0.5 & 0.0 & 0.0 \\
\hline & & 6 & 0.5 & 0.0 & 0.0 \\
\hline
\end{tabular}




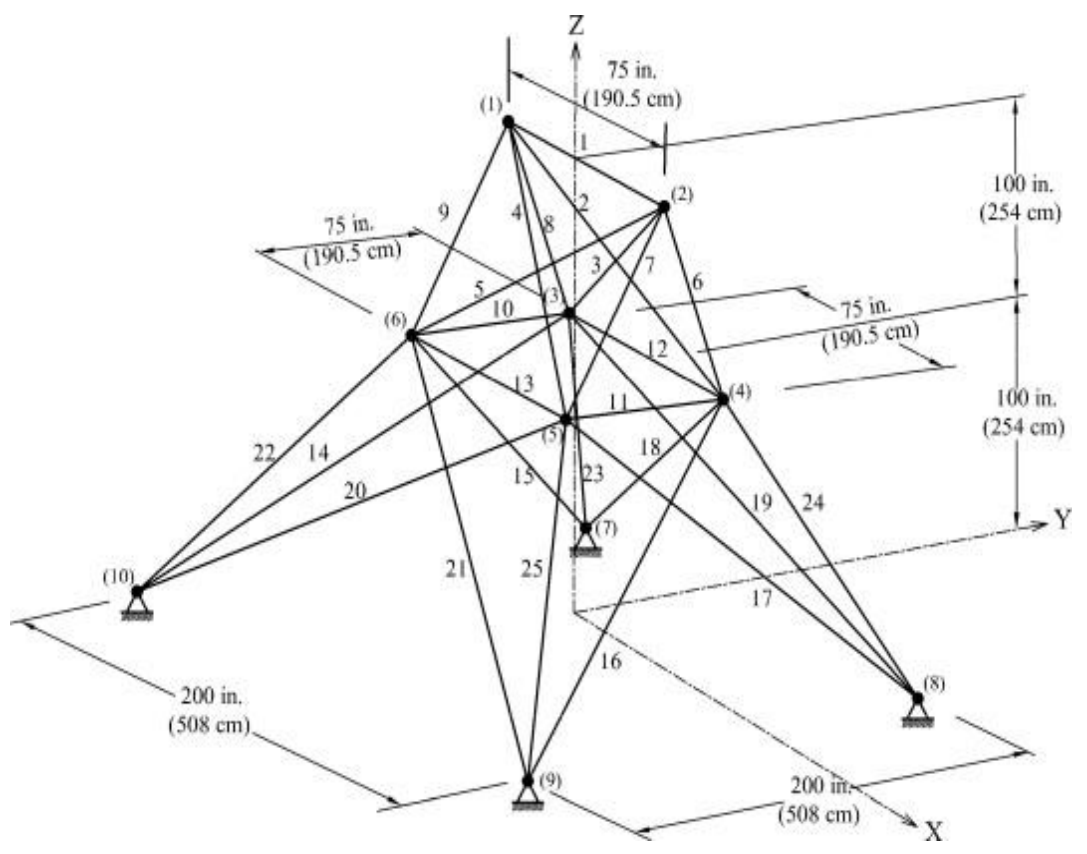

Figure 5. Schematic of 25-bar space truss.

For this design example, $\mathrm{HHO}$ was able to obtain the best design after 2214 structural iterations as shown in Figure 6. Table 4 shows that although HS, HPSO, SA, BB-BC, and ECBO found the best design, HHO has the lowest average (it reaches the best design in every run).

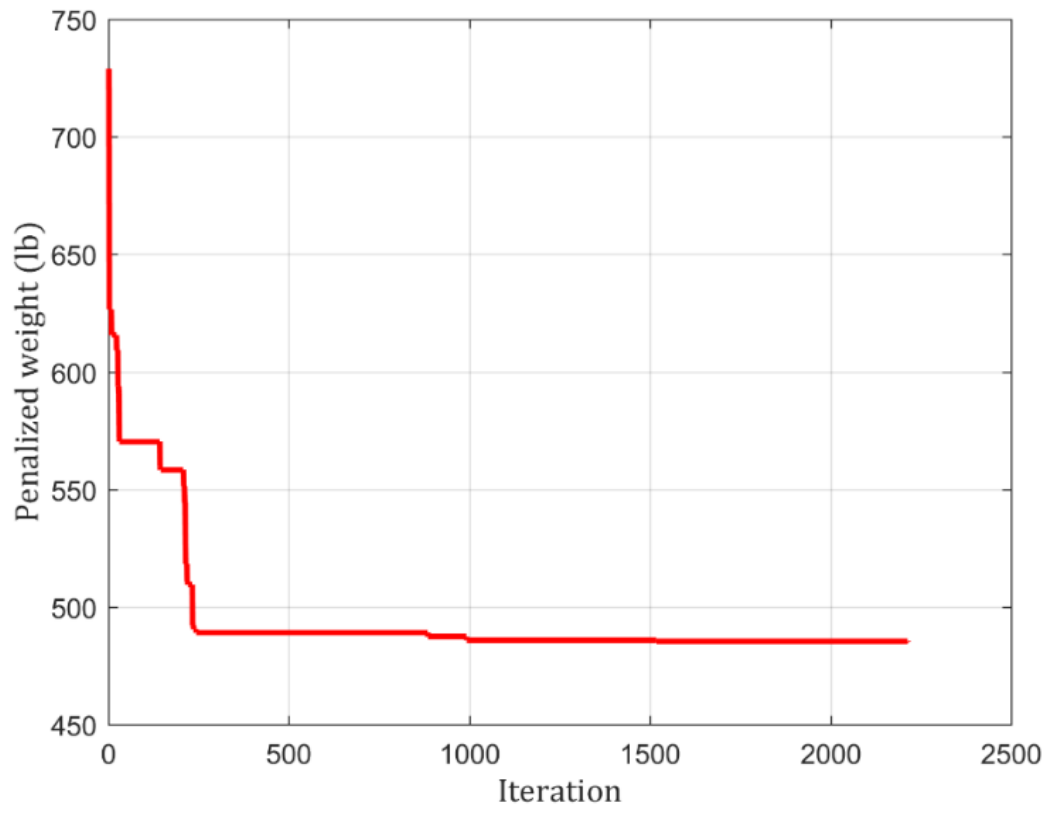

Figure 6. Convergence curve for 25-bar spatial truss (best run). 
Table 4. Performance comparison for the 25-bar spatial truss.

\begin{tabular}{|c|c|c|c|c|c|c|c|c|}
\hline \multicolumn{2}{|c|}{ Design variable $\left(\right.$ in $\left.^{2}\right)$} & \multirow{2}{*}{$\begin{array}{c}\text { GA } \\
\text { (Rajeev and } \\
\text { Krishnamooy, } \\
\text { 1992) } \\
0.1 \\
\end{array}$} & \multirow{2}{*}{$\begin{array}{c}\begin{array}{c}\text { HS } \\
\text { (Lee et } \\
\text { al., 2005) }\end{array} \\
0.1\end{array}$} & \multirow{2}{*}{$\begin{array}{c}\text { HPSO } \\
\text { (Li et al., } \\
\text { 2009) }\end{array}$} & \multirow{2}{*}{$\begin{array}{c}\begin{array}{c}\text { SA } \\
\text { (Xiang et } \\
\text { al., 2009) }\end{array} \\
0.1 \\
\end{array}$} & \multirow{2}{*}{$\begin{array}{c}\begin{array}{c}\text { BB-BC } \\
\text { (Camp, } \\
\text { 2007) }\end{array} \\
0.1 \\
\end{array}$} & \multirow{2}{*}{$\begin{array}{c}\begin{array}{c}\text { ECBO } \\
\text { (Kaveh and } \\
\text { Mahdavi, } \\
\text { 2015) }\end{array} \\
0.1 \\
\end{array}$} & \multirow{2}{*}{$\begin{array}{c}\text { HHO } \\
0.1 \\
\end{array}$} \\
\hline 1 & Area $_{1}$ & & & & & & & \\
\hline 2 & Area $_{2}-$ Area $_{5}$ & 1.8 & 0.3 & 0.3 & 0.3 & 0.3 & 0.3 & 0.3 \\
\hline 3 & Area $_{6}$-Area 9 & 2.3 & 3.4 & 3.4 & 3.4 & 3.4 & 3.4 & 3.4 \\
\hline 4 & Area $_{10}-$ Area $_{11}$ & 0.2 & 0.1 & 0.1 & 0.1 & 0.1 & 0.1 & 0.1 \\
\hline 5 & Area $_{12}-$ Area $_{13}$ & 0.1 & 2.1 & 2.1 & 2.1 & 2.1 & 2.1 & 2.1 \\
\hline 6 & Area $_{14}-$ Area $_{17}$ & 0.8 & 1.0 & 1.0 & 1.0 & 1.0 & 1.0 & 1.0 \\
\hline 7 & Area $_{18}-$ Area $_{21}$ & 1.8 & 0.5 & 0.5 & 0.5 & 0.5 & 0.5 & 0.5 \\
\hline 8 & Area $_{22}-$ Area $_{25}$ & 3.0 & 3.4 & 3.4 & 3.4 & 3.4 & 3.4 & 3.4 \\
\hline \multicolumn{2}{|c|}{ Best weight (lb) } & 546.013 & 484.854 & 484.854 & 484.854 & 484.854 & 484.854 & 484.854 \\
\hline \multicolumn{2}{|c|}{$G$ (Eq. 5) } & 0.0 & 0.0 & 0.0 & 0.0 & 0.0 & 0.0 & 0.0 \\
\hline \multicolumn{2}{|c|}{ Average weight (lb) } & N/A & N/A & N/A & $486.354^{\mathrm{b}}$ & $485.10^{c}$ & $485.89^{\mathrm{d}}$ & 484.854 \\
\hline \multicolumn{2}{|c|}{ SD weight (lb) } & N/A & N/A & N/A & N/A & 0.44 & N/A & 0.0 \\
\hline
\end{tabular}

\subsection{Planar Fifty-Two Bars Truss}

The configuration of this truss is shown in Figure 7. This example was solved in $\mathrm{Wu}$ and Chow (1995), Li et al. (2009), and Kaveh and Talatahari (2009). For all members, the Young's modulus is $207 \mathrm{GPa}$ and material density is $7860 \mathrm{~kg} / \mathrm{m}^{3}$. The stress in all members must not exceed \pm 180 MPa.The structure is subjected to vertical and horizontal point loads at the upper nodes $(17,18,19$, and 20), where $P_{x}$ is $100 \mathrm{kN}$ and $P_{y}$ is $200 \mathrm{kN}$. The structure includes 52 members organized into 12 groups (Table 5). Members are chosen form the set of 64 elements: $D=[71.613,90.968,126.451$, $161.290,198.064,252.258,285.161,363.225,388.386,494.193,506.451,641.289,645.160$, $792.256,816.773,939.998,1008.385,1045.159,1161.288,1283.868,1374.191,1535.481$, 1690.319 , 1696.771, 1858.061, 1890.319, 1993.544, 2019.351, 2180.641, 2238.705, 2290.318, 2341.931, 2477.414, 2496.769, 2503.221, 2696.769, 2722.575, 2896.768, 2961.284, 3096.768, $3206.445,3303.219,3703.218,4658.055,5141.925$, 5503.215, 5999.988, 6999.986, 7419.340, 8709.660 , 8967.724, 9161.272, 9999.980, 10322.560, 10903.204, 12129.008, 12838.684, $14193.520,14774.164,15806.420,17096.740,18064.480,19354.800,21612.860]\left(\mathrm{mm}^{2}\right)$.

HHO reaches the best design of $1902.605 \mathrm{~kg}$ after 7106 iterations (Figure 8). Table 5 shows a comparison of the best designs available in the literature along with those obtained in this study. It shows HHO finds better design than GA, HPSO, and DHPSACO. The standard deviation of 50 runs for this design example is 2.976 (note that for the previous numerical examples the standard deviation is zero). 


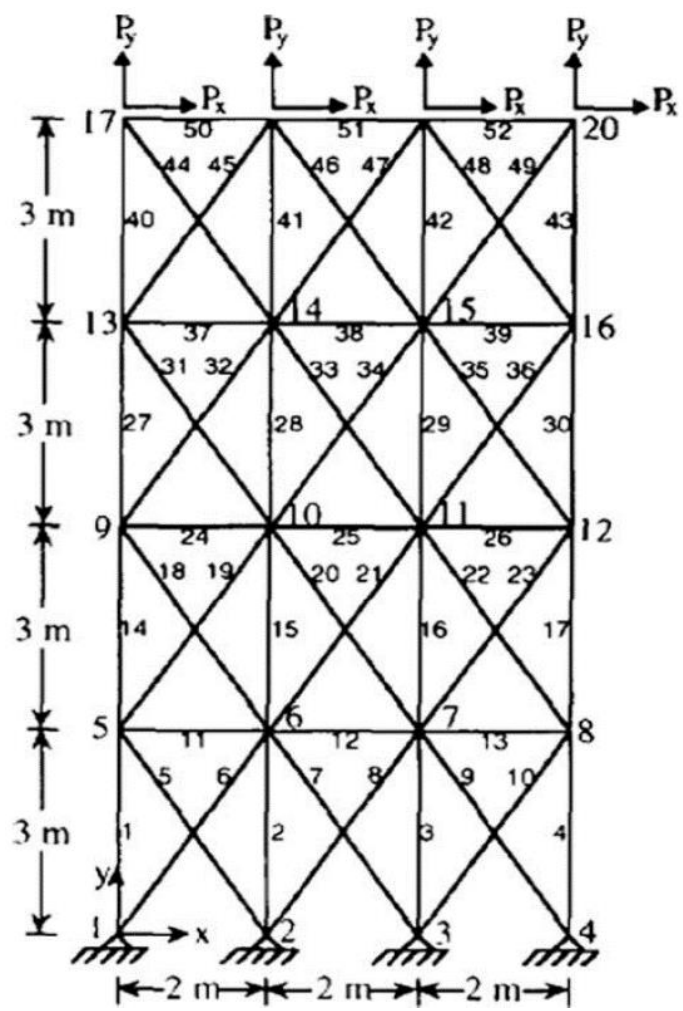

Figure 7. Configuration of 52-bar planar truss.

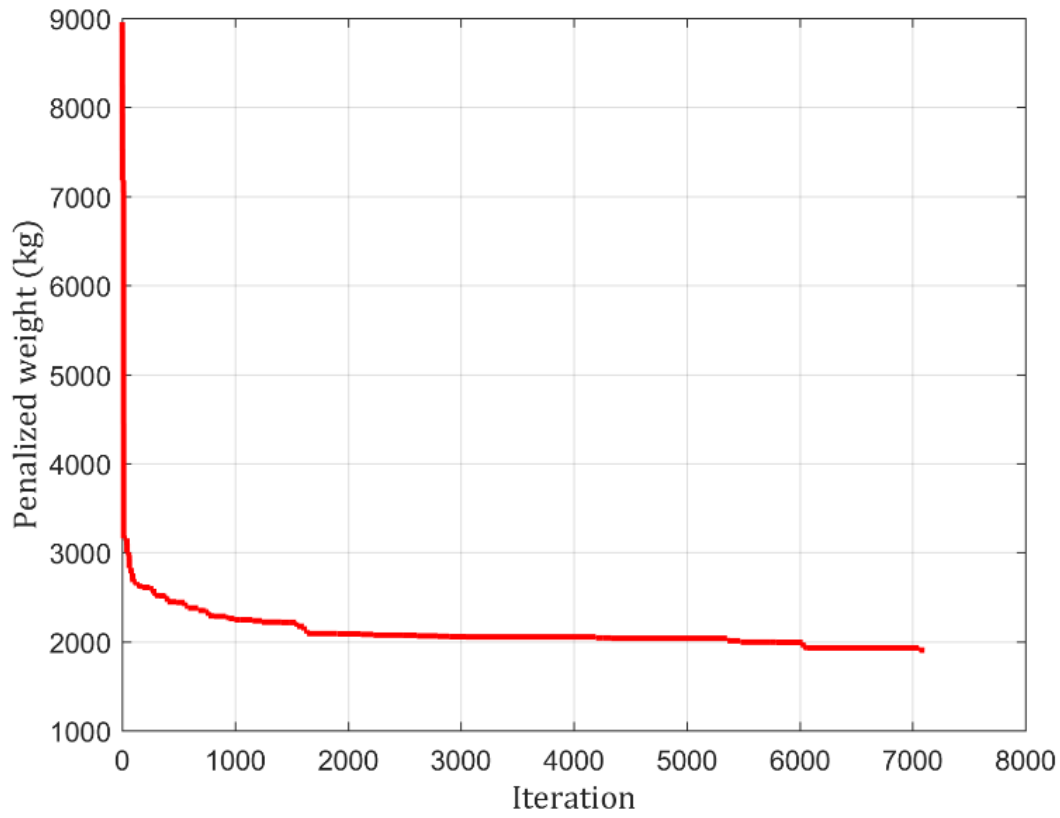

Figure 8. Convergence rate for 25-bar truss (best run). 
Table 5. Optimal designs for 52-bar truss problem.

\begin{tabular}{|c|c|c|c|c|c|}
\hline \multicolumn{2}{|c|}{ Design variable $\left(\mathbf{m m}^{2}\right)$} & \multirow{2}{*}{$\begin{array}{c}\text { GA (Wu and Chow, } \\
\text { 1995) }\end{array}$} & \multirow{2}{*}{$\begin{array}{c}\begin{array}{c}\text { HPSO (Li et al., } \\
\text { 2009) }\end{array} \\
4658.055\end{array}$} & \multirow{2}{*}{$\begin{array}{c}\begin{array}{c}\text { DHPSACO (Kaveh and } \\
\text { Talatahari, 2009) }\end{array} \\
4658.005\end{array}$} & \multirow{2}{*}{$\begin{array}{c}\text { HHO } \\
4658.055\end{array}$} \\
\hline 1 & Area $_{1}-$ Area $_{4}$ & & & & \\
\hline 2 & Area $_{5}-$ Area $_{10}$ & 1161.288 & 1161.288 & 1161.288 & 116.1288 \\
\hline 3 & Area $_{11}-$ Area $_{13}$ & 645.160 & 363.225 & 494.193 & 494.193 \\
\hline 4 & Area $_{14}-$ Area $_{17}$ & 3303.219 & 3303.219 & 3303.219 & 3303.219 \\
\hline 5 & Area $_{18}-$ Area $_{23}$ & 1045.159 & 940.000 & 1008.385 & 939.998 \\
\hline 6 & Area $_{24}-$ Area $_{30}$ & 494.193 & 494.193 & 285.161 & 494.193 \\
\hline 7 & Area $_{31}-$ Area $_{34}$ & 2477.414 & 2238.705 & 2290.318 & 2238.705 \\
\hline 8 & Area $_{35}-$ Area $_{36}$ & 1045.159 & 1008.385 & 1008.385 & 1008.385 \\
\hline 9 & Area $_{37}-$ Area $_{39}$ & 285.161 & 388.386 & 388.386 & 494.193 \\
\hline 10 & Area $_{40}-$ Area $_{43}$ & 1696.771 & 1283.868 & 1283.868 & 1283.868 \\
\hline 11 & Area $_{44}-$ Area $_{49}$ & 1045.159 & 1161.288 & 1161.288 & 1161.288 \\
\hline 12 & Area $_{50}-$ Area $_{52}$ & 641.289 & 792.256 & 506.451 & 494.193 \\
\hline \multicolumn{2}{|r|}{ Best mass $(\mathrm{kg})$} & 1972.652 & 1905.496 & 1904.827 & 1902.605 \\
\hline \multicolumn{2}{|r|}{$G$ (Eq. 5) } & None & None & $2.72 \times 10^{-3}$ & 0.0 \\
\hline \multicolumn{2}{|c|}{ Average mass $(\mathrm{kg})$} & N/A & N/A & N/A & 1905.190 \\
\hline \multicolumn{2}{|r|}{ SD mass $(\mathrm{kg})$} & N/A & N/A & N/A & 2.976 \\
\hline
\end{tabular}

\subsection{Spatial Seventy-Two Bars Truss}

The configuration of this design example is shown in Figure 9. This example was solved in Li et al. (2009), Kaveh and Khayatazad (2012), and Kaveh and Mahdavi (2015). For all members, the Young's modulus is $10000 \mathrm{ksi}$ and the material density is $0.1 \mathrm{lb} / \mathrm{in} 3$. The maximum permissible displacement for all joints in both $\mathrm{X}$ and $\mathrm{Y}$ directions equals \pm 0.25 in. The stress limit for all members is $\pm 25 \mathrm{ksi}$. Two loading conditions are applied as explained in Table 6 . The structure includes 72 members organized into 16 groups (Table 7). Design variables are selected from the discrete set of 64: $D=[0.111,0.141,0.196,0.250,0.307,0.391,0.442,0.563,0.602,0.766,0.785$, $0.994,1.000,1.228,1.266,1.457,1.563,1.620,1.800,1.990,2.130,2.380,2.620,2.630,2.880$, $2.930,3.090,3.13,3.380,3.470,3.550,3.630,3.840,3.870,3.880,4.180,4.220,4.490,4.590$, $4.800,4.970,5.120,5.740,7.220,7.970,8.530,9.300,10.850,11.500,13.500,13.900,14.200$, $15.500,16.000,16.900,18.800,19.900,22.000,22.900,24.500,26.500,28.000,30.000,33.500]$ $\left(\mathrm{in}^{2}\right)$.

Table 7 provides some best designs available in the literature along with those obtained in this research. HHO obtained the best design after 5237 iterations (Figure 10). The best structural weight of $389.334 \mathrm{lb}$ was obtained by IRO, ECBO, and HHO. However, the average of 50 runs of $\mathrm{HHO}$ shows it has the lowest average value.

Table 6. Loading cases of the spatial 72-bat truss.

\begin{tabular}{|c|c|c|c|c|}
\hline \multirow{2}{*}{ Case } & \multirow{2}{*}{ Nodes } & \multicolumn{3}{|c|}{ Loads (kips) } \\
\cline { 3 - 5 } & & $\mathbf{P}_{\mathbf{x}}$ & $\mathbf{P}_{\mathbf{y}}$ & $\mathbf{P}_{\mathbf{z}}$ \\
\hline \multirow{3}{*}{2} & 17 & 5.0 & 5.0 & -5.0 \\
\hline \multirow{3}{*}{2} & 17 & 0.0 & 0.0 & -5.0 \\
\cline { 2 - 5 } & 18 & 0.0 & 0.0 & -5.0 \\
\cline { 2 - 5 } & 19 & 0.0 & 0.0 & -5.0 \\
\cline { 2 - 5 } & 20 & 0.0 & 0.0 & -5.0 \\
\hline
\end{tabular}




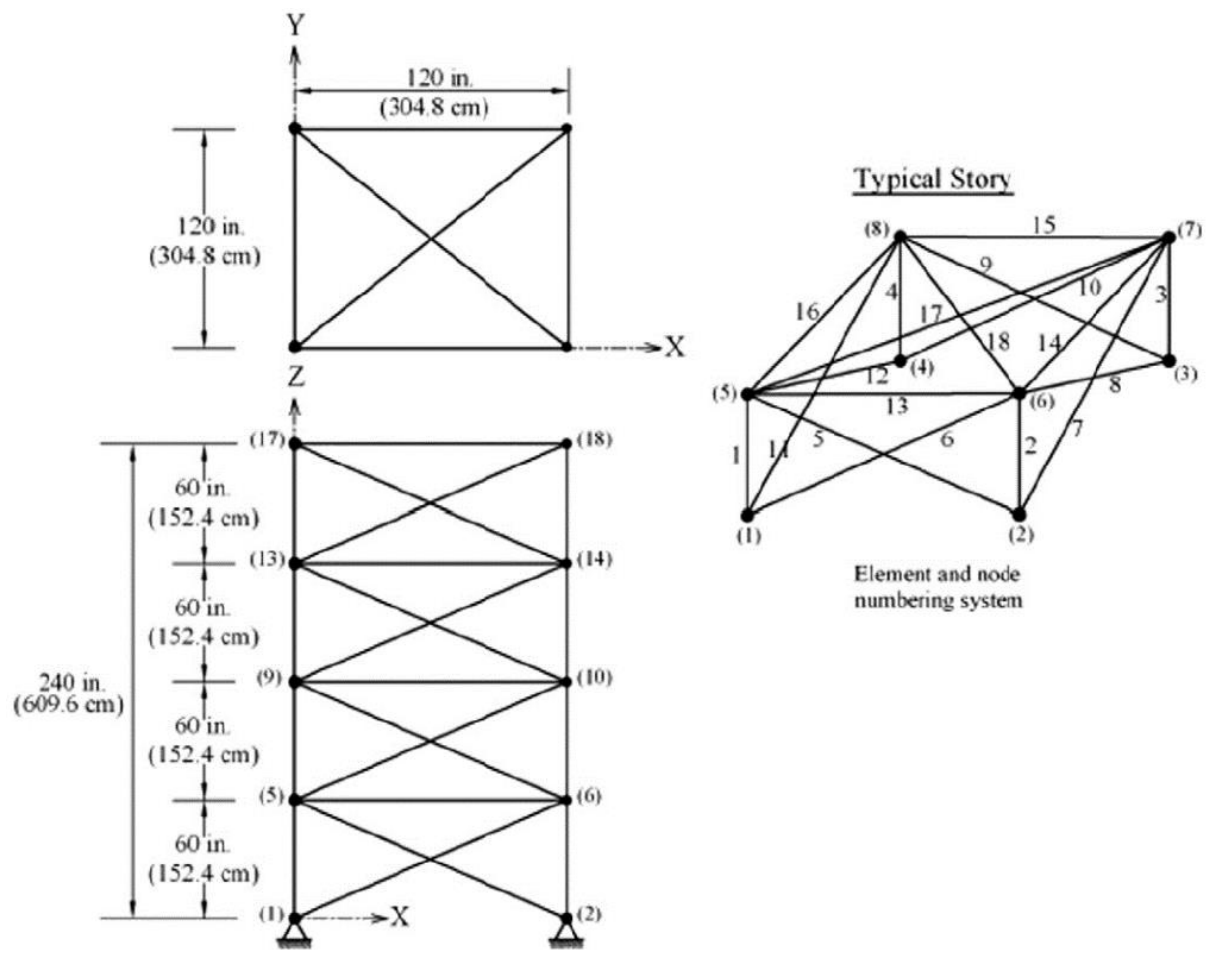

Figure 9. Schematic of 72-bar space truss.

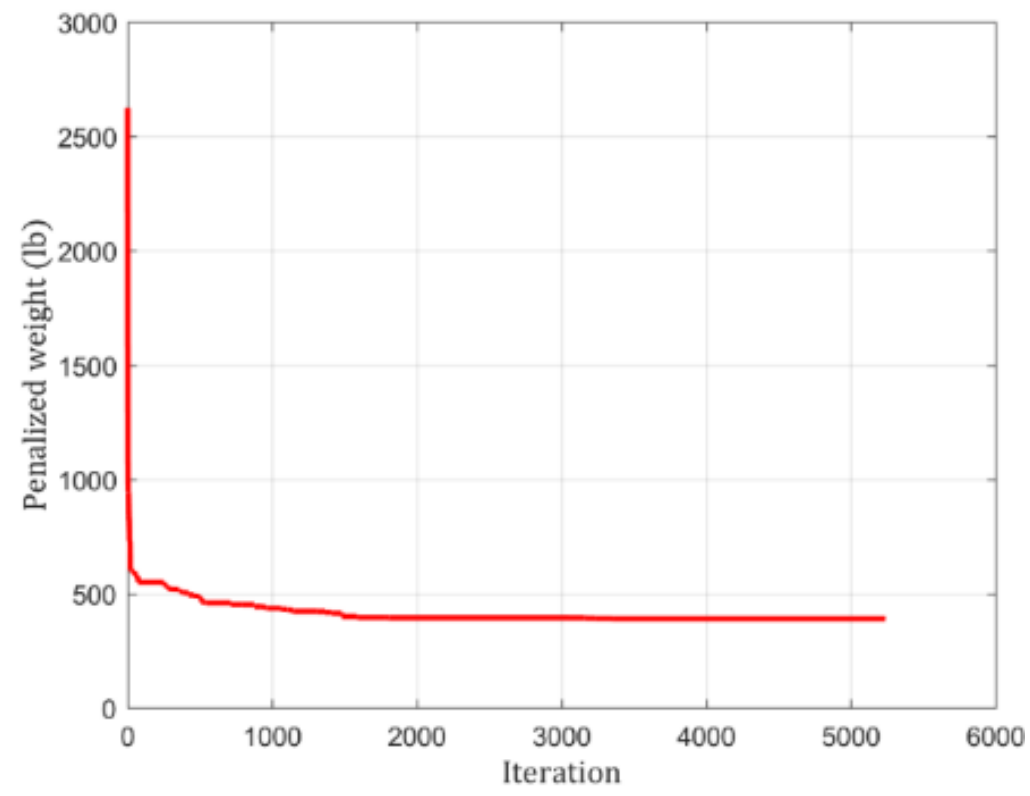

Figure 10. Convergence curve for 72-bar spatial truss (best run). 
Table 7. Optimal designs for the 72-bar truss.

\begin{tabular}{|c|c|c|c|c|c|c|}
\hline \multicolumn{2}{|c|}{ Design variable $\left(\mathrm{in}^{2}\right)$} & \multirow{2}{*}{$\begin{array}{c}\text { HPSO } \\
\text { (Li et al., } \\
2009) \\
4.970 \\
\end{array}$} & \multirow{2}{*}{$\begin{array}{c}\text { IRO } \\
\text { (Kaveh and } \\
\text { Khayatazad, } \\
2012 \text { ) } \\
1.990 \\
\end{array}$} & \multirow{2}{*}{$\begin{array}{c}\text { CBO } \\
\text { (Kaveh and } \\
\text { Mahdavi, } \\
2015 \text { ) } \\
2.130 \\
\end{array}$} & \multirow{2}{*}{$\begin{array}{c}\text { ECBO } \\
\text { (Kaveh and } \\
\text { Mahdavi, } \\
2015 \text { ) } \\
1.990 \\
\end{array}$} & \multirow{2}{*}{$\begin{array}{l}\text { HHO } \\
1.990 \\
\end{array}$} \\
\hline 1 & Area $_{1}-$ Area $_{4}$ & & & & & \\
\hline 2 & Area $_{5}-$ Area $_{12}$ & 1.228 & 0.563 & 0.563 & 0.563 & 0.563 \\
\hline 3 & Area $_{13}-$ Area $_{16}$ & 0.111 & 0.111 & 0.111 & 0.111 & 0.111 \\
\hline 4 & Area $_{17}-$ Area $_{18}$ & 0.111 & 0.111 & 0.111 & 0.111 & 0.111 \\
\hline 5 & Area $_{19}-$ Area $_{22}$ & 2.880 & 1.228 & 1.228 & 1.228 & 1.228 \\
\hline 6 & Area $_{23}-$ Area $_{30}$ & 1.457 & 0.442 & 0.442 & 0.442 & 0.442 \\
\hline 7 & Area $_{31}-$ Area $_{34}$ & 0.141 & 0.111 & 0.141 & 0.111 & 0.111 \\
\hline 8 & Area $_{35}-$ Area $_{36}$ & 0.111 & 0.111 & 0.111 & 0.111 & 0.111 \\
\hline 9 & Area $_{37}-$ Area $_{40}$ & 1.563 & 0.563 & 0.442 & 0.563 & 0.563 \\
\hline 10 & Area $_{41}-$ Area $_{48}$ & 1.228 & 0.563 & 0.563 & 0.563 & 0.563 \\
\hline 11 & Area $_{49}-$ Area $_{52}$ & 0.111 & 0.111 & 0.111 & 0.111 & 0.111 \\
\hline 12 & Area $_{53}-$ Area $_{54}$ & 0.196 & 0.111 & 0.111 & 0.111 & 0.111 \\
\hline 13 & Area $_{55}-$ Area $_{58}$ & 0.391 & 0.196 & 0.196 & 0.196 & 0.196 \\
\hline 14 & Area $_{59}-$ Area $_{66}$ & 1.457 & 0.563 & 0.563 & 0.563 & 0.563 \\
\hline 15 & Area $_{67}-$ Area $_{70}$ & 0.766 & 0.391 & 0.391 & 0.391 & 0.391 \\
\hline 16 & Area $_{71}-$ Area $_{72}$ & 1.563 & 0.563 & 0.563 & 0.563 & 0.563 \\
\hline \multicolumn{2}{|c|}{ Best weight (lb) } & 933.094 & 389.334 & 391.230 & 389.334 & 389.334 \\
\hline \multicolumn{2}{|c|}{$G(\mathrm{Eq} .5)$} & 0.0 & 0.0 & 0.0 & 0.0 & 0.0 \\
\hline \multicolumn{2}{|c|}{ Average weight (lb) } & N/A & 408.17 & 456.69 & $391.59^{\mathrm{b}}$ & 389.818 \\
\hline \multicolumn{2}{|c|}{ SD weight $(\mathrm{lb})$} & N/A & N/A & N/A & N/A & 0.696 \\
\hline
\end{tabular}

\section{Concluding Remarks}

Harris Hawks Optimization (HHO) is a stochastic algorithm mimicking the behavior of Harris hawks of chasing a prey. Previously, HHO was used to solve mechanical, chemical, electrical engineering optimization problems with design variables that are continuous. In this research, $\mathrm{HHO}$ was utilized to solve truss structure optimization problems with discrete design variables. Unlike competing metaheuristic algorithms, HHO does not require tuning of parameters. This feature improves the stability of the algorithm. The original HHO for continuous design variables is modified to suit the discrete variables problems and used to solve well-known five truss structure problems. These standard problems are considered to verify the effectiveness and stability of HHO. The comparison of the numerical results of these structures using $\mathrm{HHO}$ with those available in the literature demonstrates the consistency of the HHO. The consistency of the results is shown by the small standard deviations and lowest averages of final cost function values of 50 independent runs. This implies that fewer runs are needed to obtain the best design in comparison with many other metaheuristic algorithms. Also, HHO shows good convergence speed. For future work, it is suggested to use Harris Hawks Optimization to solve more complex structural optimization problems such as frame structures and large-scale trusses.

Conflict of Interest

For this publication, the author ensures that there is no conflict of interest to declare.

\section{Acknowledgments}

The author wishes to show his appreciation to the editor and reviews for their valuable suggestions. 


\section{References}

Al-Bazoon, M.C.J. (2019). Damage-tolerant optimal design of structures subjected to blast loading. (Doctor of Philosophy (PhD)), University of Iowa. DOI https://doi.org/10.17077/etd.49zn-2716.

Arora, J.S. (2017). Introduction to optimum design (4th ed.). Elsevier.

Camp, C.V. (2007). Design of space trusses using big bang-big crunch optimization. Journal of Structural Engineering, 133(7), 999-1008. https://doi.org/10.1061/(ASCE)0733-9445(2007)133:7(999).

Ewees, A.A., \& Abd Elaziz, M. (2020). Performance analysis of chaotic multi-verse harris hawks optimization: a case study on solving engineering problems. Engineering Applications of Artificial Intelligence, 88, 103370. https://doi.org/10.1016/j.engappai.2019.103370.

Goldberg, D.E., \& Samtani, M.P. (1986). Engineering optimization via genetic algorithm. In Electronic Computation, (pp. 471-482). ASCE.

Heidari, A.A., Mirjalili, S., Faris, H., Aljarah, I., Mafarja, M., \& Chen, H. (2019). Harris hawks optimization: algorithm and applications. Future Generation Computer Systems, 97, 849-872.

Houssein, E.H., Hosney, M.E., Oliva, D., Mohamed, W.M., \& Hassaballah, M. (2020). A novel hybrid harris hawks optimization and support vector machines for drug design and discovery. Computers \& Chemical Engineering, 133, 106656.

Kaveh, A., \& Khayatazad, M. (2012). A new meta-heuristic method: ray optimization. Computers \& Structures, 112, 283-294. https://doi.org/10.1016/j.compstruc.2012.09.003.

Kaveh, A., \& Mahdavi, V.R. (2015). Colliding bodies optimization: extensions and applications. Springer. Switzerland.

Kaveh, A., \& Talatahari, S. (2009). Particle swarm optimizer, ant colony strategy and harmony search scheme hybridized for optimization of truss structures. Computers \& Structures, 87(5-6), 267-283.

Kennedy, J., \& Eberhart, R. (1995). Particle swarm optimization. Proceedings of ICNN'95-International Conference on Neural Networks, 4. Perth, WA, Australia. DOI: 10.1109/ICNN.1995.488968.

Lee, K.S., Geem, Z.W., Lee, S.H., \& Bae, K.W. (2005). The harmony search heuristic algorithm for discrete structural optimization. Engineering Optimization, 37(7), 663-684.

Li, L.I., Ren, F.M., Liu, F., \& Wu, Q.H. (2006). An improved particle swarm optimization method and its application in civil engineering. Proceedings of International Conference on Engineering Computational Technology.

Li, L.J., Huang, Z.B., \& Liu, F. (2009). A heuristic particle swarm optimization method for truss structures with discrete variables. Computers \& Structures, 87(7-8), 435-443.

Rajeev, S., \& Krishnamoorthy, C.S. (1992). Discrete optimization of structures using genetic algorithms. Journal of Structural Engineering, 118(5), 1233-1250. https://doi.org/10.1061/(ASCE)07339445(1992)118:5(1233).

Rodríguez-Esparza, E., Zanella-Calzada, L.A., Oliva, D., Heidari, A.A., Zaldivar, D., Pérez-Cisneros, M., \& Foong, L.K. (2020). An efficient harris hawks-inspired image segmentation method. Expert Systems with Applications, 155, 113428.

Wu, S.J., \& Chow, P.T. (1995). Steady-state genetic algorithms for discrete optimization of trusses. Computers \& Structures, 56(6), 979-991. https://doi.org/10.1016/0045-7949(94)00551-D.

Wunnava, A., Naik, M.K., Panda, R., Jena, B., \& Abraham, A. (2020). An adaptive harris hawks optimization technique for two dimensional grey gradient based multilevel image thresholding. Applied Soft Computing, 95, 106526. https://doi.org/10.1016/j.asoc.2020.106526. 
Xiang, B.W., Chen, R.Q., \& Zhang, T. (2009). Optimization of trusses using simulated annealing for discrete variables. Paper presented at the 2009 International Conference on Image Analysis and Signal Processing. Linhai, China.

Xie, Y.M., \& Steven, G.P. (1997). Basic evolutionary structural optimization. In Evolutionary Structural Optimization (pp. 12-29). Springer. https://doi.org/10.1007/978-1-4471-0985-3_2.

Yu, J., Kim, C.H., \& Rhee, S.B. (2020). The comparison of lately proposed harris hawks optimization and jaya optimization in solving directional overcurrent relays coordination problem. Complexity, 2020. https://doi.org/10.1155/2020/3807653. 